\title{
Impact of Atmospheric Plasma Spray Parameters on Cavitation Erosion Resistance of $\mathrm{Al}_{2} \mathrm{O}_{3}-13 \% \mathrm{TiO}_{2}$ Coatings
}

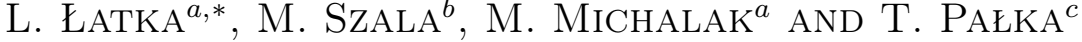 \\ ${ }^{a}$ Mechanical Department, Wrocław University of Science and Technology, \\ Łukasiewicza St. 5, 50-371, Wrocław, Poland \\ ${ }^{b}$ Lublin University of Technology, Faculty of Mechanical Engineering, Department of Materials Engineering, \\ Nadbystrzycka St. 36, 20-618 Lublin, Poland \\ ${ }^{c}$ Lublin University of Technology, Faculty of Mechanical Engineering, Production, \\ Nadbystrzycka St. 36, 20-618 Lublin, Poland

\begin{abstract}
In this paper the results of cavitation erosion test of ceramic coatings are presented. $\mathrm{The}^{\mathrm{Al}} \mathrm{Al}_{2} \mathrm{O}_{3}-13 \% \mathrm{TiO}_{2}$ coatings were manufactured by powder atmospheric plasma spraying. The plasma spray experimental parameters included two variables: (i) spray distance varying from 80 to $100 \mathrm{~mm}$ and (ii) torch linear speed varying from 300 to $500 \mathrm{~mm} / \mathrm{s}$. The as sprayed surface roughness was measured. The coatings structure was investigated using SEM. Porosity was investigated according to the ASTM E2109-01 Standard procedure. Additional microhardness measurements were conducted. The cavitation tests were carried out on vibratory test rig according to the ASTM G-32 standard regarding to the stainless steel (grade 304) reference sample. The cavitational worn areas were examined using SEM microscopy and roughness measurements. The influence of coatings microstructure and microhardness on the cavitation erosion resistance was investigated. The coatings microstructure was strongly dependent on spray distance as well as torch linear velocity. Decrease of the hardness was a result of less compact structure and lower degree of well molten particle. On the contrary, the best cavitation erosion resistance was characteristic for coatings which have quite good and compact structure but on the other hand the heat flux was lower. Higher heat flux caused thermal stresses, which were visible as cracks in the structure. Moreover, the type of the structure was important because from the point of view of the cavitation erosion resistance, lamellar architecture is more preferred than the columnar one. Finally, the structure type was linked to the process parameters.
\end{abstract}

DOI: 10.12693/APhysPolA.136.342

PACS/topics: 52.77.-j, 81.15.--Z

\section{Introduction}

Nowadays thermal spraying of coatings is a relevant issue in the surface industry [1]. A lot of attention is paid to the complex deposits, derived from powders which are composed of different metals, hardmetals, and/or oxides [1-3]. One of those intensively studied powders are $\mathrm{Al}_{2} \mathrm{O}_{3}+\mathrm{TiO}_{2}$ powders, most commonly sprayed with the Atmospheric Plasma Spraying (APS) method [1]. Such powders combined from two oxides $\left(\mathrm{Al}_{2} \mathrm{O}_{3}\right.$ and $\mathrm{TiO}_{2}$ ) have better technological properties than each of them separately [2]. The addition of $\mathrm{TiO}_{2}$ to $\mathrm{Al}_{2} \mathrm{O}_{3}$ results in lower melting point of the $\mathrm{Al}_{2} \mathrm{O}_{3}+\mathrm{TiO}_{2}$ powder, and thus enables the production of less porous and more durable coatings [4]. The most commonly used $\mathrm{Al}_{2} \mathrm{O}_{3}+\mathrm{TiO}_{2}$ powders are: $\mathrm{Al}_{2} \mathrm{O}_{3} 3 \mathrm{wt} \% \mathrm{TiO}_{2}, \mathrm{Al}_{2} \mathrm{O}_{3}$ +13 wt $\% \mathrm{TiO}_{2}$, and $\mathrm{Al}_{2} \mathrm{O}_{3}+40 \mathrm{wt} \% \mathrm{TiO}_{2}[5-9]$. All of those powders are of high hardness, good wear-, abrasion-, and thermal shock- resistance and have high impact strength [5-8]. Although, $\mathrm{Al}_{2} \mathrm{O}_{3}+13 \mathrm{wt} \% \mathrm{TiO}_{2}$ are known to provide the optimal wear properties [10,11].

$\mathrm{Al}_{2} \mathrm{O}_{3}$ and $\mathrm{TiO}_{2}$ are one of the most useful and ver-

*corresponding author; e-mail: leszek.latka@pwr.edu.pl satile materials [12]: the plasma sprayed $\mathrm{Al}_{2} \mathrm{O}_{3}+\mathrm{TiO}_{2}$ coatings are applied in many industries, such as printing, textile, logistics, automotive, cosmonautics, and aviation ones [10,13-18]. Dense, homogeneous $\mathrm{Al}_{2} \mathrm{O}_{3}+\mathrm{TiO}_{2}$ coatings are especially desired for printing rollers (due to high wear resistance against the pigment contained in the ink) and for the thread spools (owing to their wear resistance to fibers) $[6,7,12,19]$. Additionally, these coatings can be of significant interest for oil, gas, transmission and marine industries-which face corrosion problems. Due to the combination of wear-, oxidationand aggressive environments- resistance, the application of such coatings could protect parts working under severe conditions [11, 20-24]. Although papers report promising results regarding application of APS titaniaalumina based coatings for improvement of cavitation erosion resistance (CER) $[18,25]$, it seems that influence of spray parameters has not been completely investigated. In the industrial applications, the selection of basic APS process parameters (i.e. distance between the torch and the substrate as well as the linear velocity between the sprayed element and the torch) usually comes from the sprayed component geometry. Influence of the mentioned parameters on CER is neglected in the literature. Similarly Jafarzadeh et al. [18] investigated only the effect of powder feeding rate and hydrogen gas flow rate on $\mathrm{CER}$ of $\mathrm{Al}_{2} \mathrm{O}_{3}+13 \mathrm{wt} \% \mathrm{TiO}_{2}$ coatings. 
Moreover, surface morphology and mechanical properties of the coatings are strongly affected by the conditions of spraying (e.g. spray parameters, substrate preheating) and consequently the effect on CER of thermallysprayed coatings $[9,18,26,27]$. In this paper, the coatings were deposited by the APS technique. During spraying, the feedstock powder particles of the size from 20 to $100 \mu \mathrm{m}$ are melted in the plasma plum and subsequently deposited onto the prepared substrate [28]. On one hand, it is an industrially approved method, but on the other hand - this is also a very versatile one $[28,29]$. It is estimated [30] that the APS method is based on over 50 variables of this process. The literature is more and more involved in explanation of the relationships which take place during spraying and the influence of spraying parameters on coatings functional properties such as resistance to wear $[11,17,18,27]$.

The aim of the paper is to investigate the influence of plasma spray parameters on coatings properties (hardness, surface morphology, and microstructure) and cavitation erosion resistance.

\section{Materials and methods}

Plasma spraying was performed using a single cathode torch (SG-100, Praxair) which was mounted on the 6-axis industrial robot (Fanuc 2000 IA). The feeding material was Metco 6221, a commercially available powder of the composition $\mathrm{Al}_{2} \mathrm{O}_{3}+13 \mathrm{wt} \% \mathrm{TiO}_{2}$. The particle size distribution was $\sim 45 \pm 15 \mu \mathrm{m}$. The morphology of the initial powder is shown in Fig. 1.

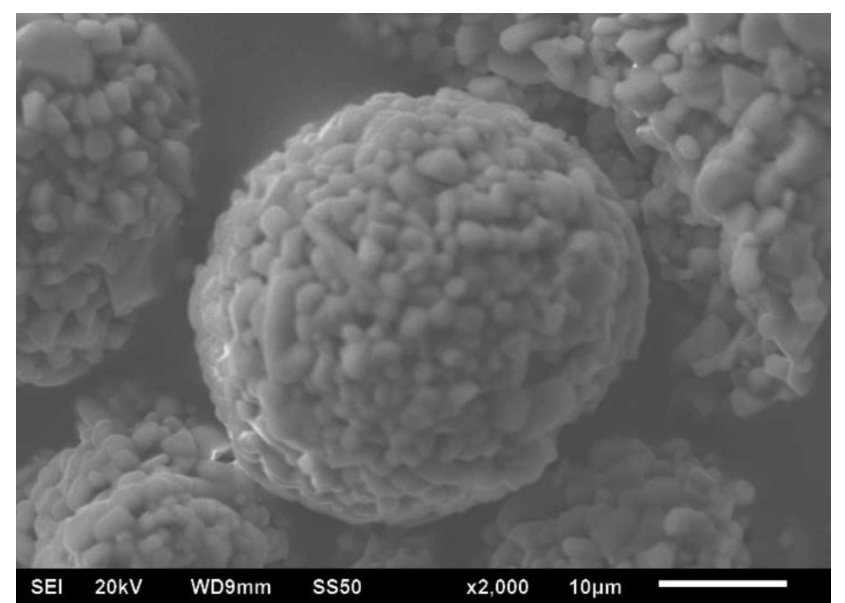

Fig. 1. SEM image of $\mathrm{Al}_{2} \mathrm{O}_{3} 13 \mathrm{wt} \% \mathrm{TiO}_{2}$ powder under the delivery condition.

The working gases composition was 45 slpm of Ar and 5 slpm of $\mathrm{H}_{2}$. The coatings were deposited on the stainless steel substrates $(25 \mathrm{~mm}$ diameter and $2 \mathrm{~mm}$ thickness) which were cleaned with ethanol and sand blasted using the corundum before the deposition. The research was carried out according to experimental design presented in [31] and the experiment scheme was $2^{n}+1$,
Sample code and variable process parameters

TABLE I

\begin{tabular}{c|c|c}
\hline \hline $\begin{array}{c}\text { Sample } \\
\text { code }\end{array}$ & $\begin{array}{c}\text { Spray distance, } \\
h[\mathrm{~mm}]\end{array}$ & $\begin{array}{c}\text { Torch velocity, } \\
V[\mathrm{~mm} / \mathrm{s}]\end{array}$ \\
\hline AT13-1 & 80 & 300 \\
AT13-2 & 80 & 500 \\
AT13-3 & 90 & 400 \\
AT13-4 & 100 & 300 \\
AT13-5 & 100 & 500
\end{tabular}

where $n$ was equal to 2 , i.e. the spray distance and velocity of the plasma torch. The details are collected in Table I.

After the metallographic preparation the coating surfaces and cross sections were studied using the scanning electron microscopes JEOL JSM-6610A and PHENOM G2 PRO. The porosity of the coatings was evaluated by the image analysis method which allows to detect open and close porosity, which is a very important task in the case of plasma spray coatings. According to the ASTM Standard [32], at least 20 images should be analysed to obtain reliable results.

Microhardness of the coatings was measured with the Vickers penetrator under the load of $0.98 \mathrm{~N}$ (HV0.1) on the Sinowon apparatus and 10 indentations in random locations of the coating cross-section were made. Porosity and hardness mean values and standard deviations were calculated.

The cavitation tests were carried out on an ultrasonic test stand using the apparatus conforming the ASTM G-32 standard [33] recommendations, according to an alternative stationary specimen method which is dedicated for coatings testing. The gap between the sonotrode tip and the test surface was set equal to $1 \pm 0.05 \mathrm{~mm}$, the amplitude and frequency of the tests were $50 \mu \mathrm{m}$ and $20 \mathrm{kHz}$, respectively. The titanium sonotrode tip diameter was $15.9 \mathrm{~mm}$. Distilled water was used as a cavitation test medium. The water temperature was stabilised at $25 \pm 2{ }^{\circ} \mathrm{C}$. The mass losses of tested specimens were measured periodically using an analytical balance with an accuracy of $0.1 \mathrm{mg}$. Three measurements of each sample were investigated. The MED (mean depth of erosion), MER (mean erosion rate), and $\mathrm{Ne}$ (normalised erosion resistance) were determined according to $[9,33,34]$. Coatings in the as-sprayed and reference stainless steel grade AISI 304 were tested under the as-received conditions. The cavitation-worn surface of the samples were assessed with the scanning electron microscope Phenom ProX (SEM, BSD, Phenom World) and $S_{a}, S_{z}$ roughness parameters were determined by means of T8000RC 120-140 profilometer (Hommel-Etamic).

\section{Results and discussion}

The sprayed AT13 coatings (with a thickness of $\sim 180 \mu \mathrm{m}$ ) have a typical lamellar structure. There are fine, unmolten grains of a spherical shape (Fig. 2a and c). 


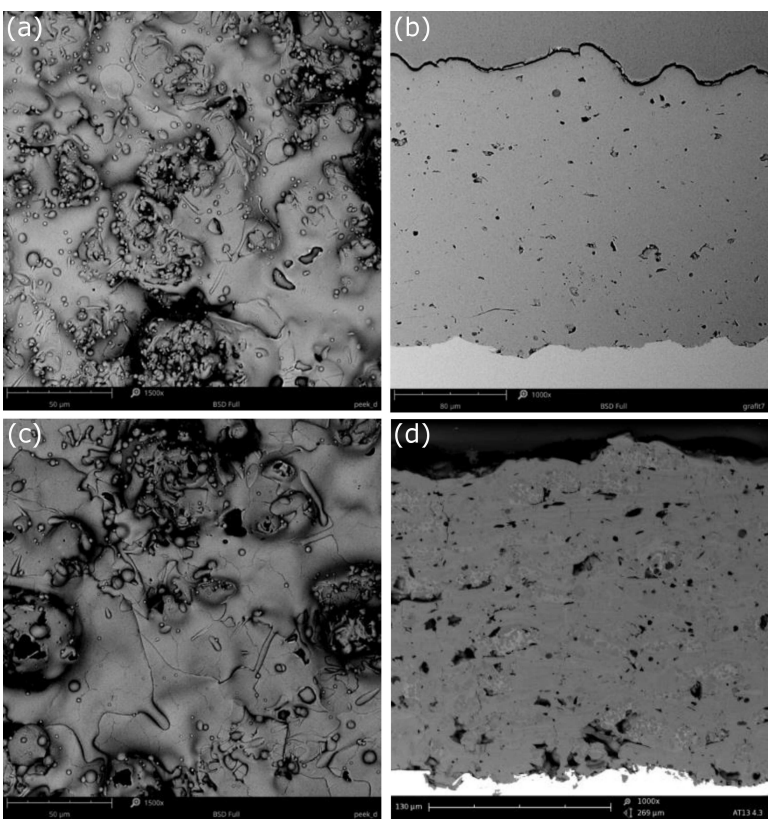

Fig. 2. Topography (left images) and cross section (right images) of the selected manufactured coatings: $(\mathrm{a}, \mathrm{b})-\mathrm{AT} 13-1$ and $(\mathrm{c}, \mathrm{d})-\mathrm{AT} 13-4$.

On the cross sections porosity and good interface between the coating and the substrate can be seen (Fig. 2b and d). The coatings are relatively dense.

The measurements of microhardness and coatings porosity were performed on the polished cross sections of the samples. In Fig. 3 dependence between decreasing porosity and increasing microharndess can be clearly observed. Besides it should be stressed that in relation to porosity of other ceramic coatings reported in the literature $[18,33]$, the level of porosity computed in our study is relatively low. As follows from the conducted analysis, decreasing microhardness correlates with the increasing spray distance and torch velocity. The observations of samples cross-section acknowledge that coating hardness is related to the spray parameters. The decreasing hardness results from a less compact structure and lower degree of well molten particle.

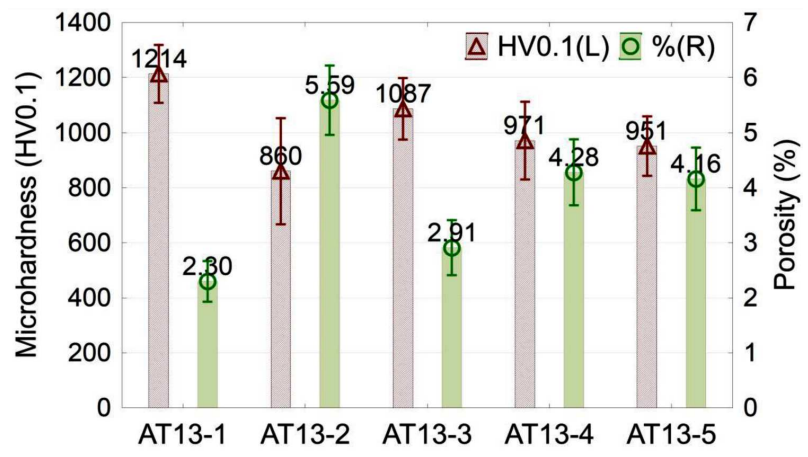

Fig. 3. Mean microhardness (HV0.1) and porosity values of sprayed coatings.
The cavitation erosion curves of $\mathrm{Al}_{2} \mathrm{O}_{3}-13 \% \quad \mathrm{TiO}_{2}$ coatings (AT13) and the reference stainless steel (304) are plotted in Fig. 4. The parameters describing the cavitation erosion process are listed in Table II. Comparison of sample surface for the as-sprayed and tested samples is given in Table III and Fig. 5 .

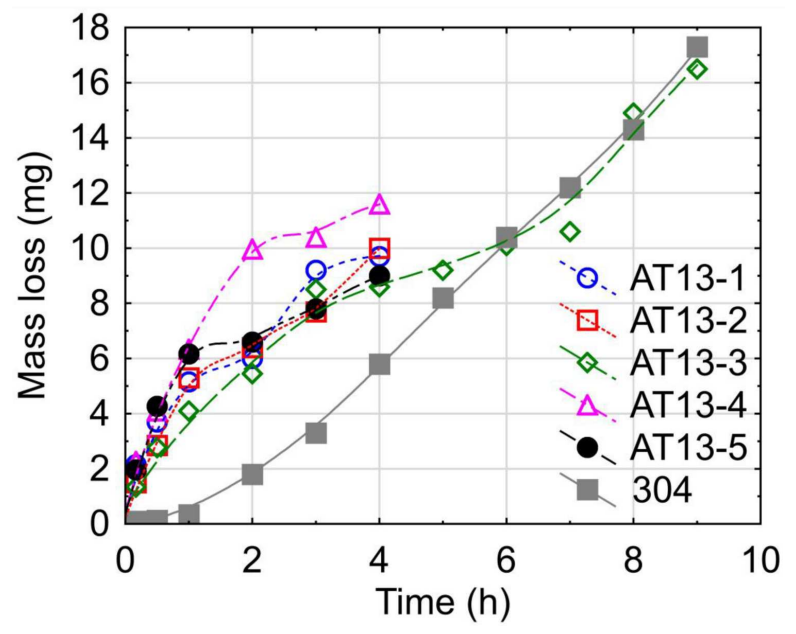

Fig. 4. Cumulative erosion-time curves of sprayed coatings and reference stainless steel.
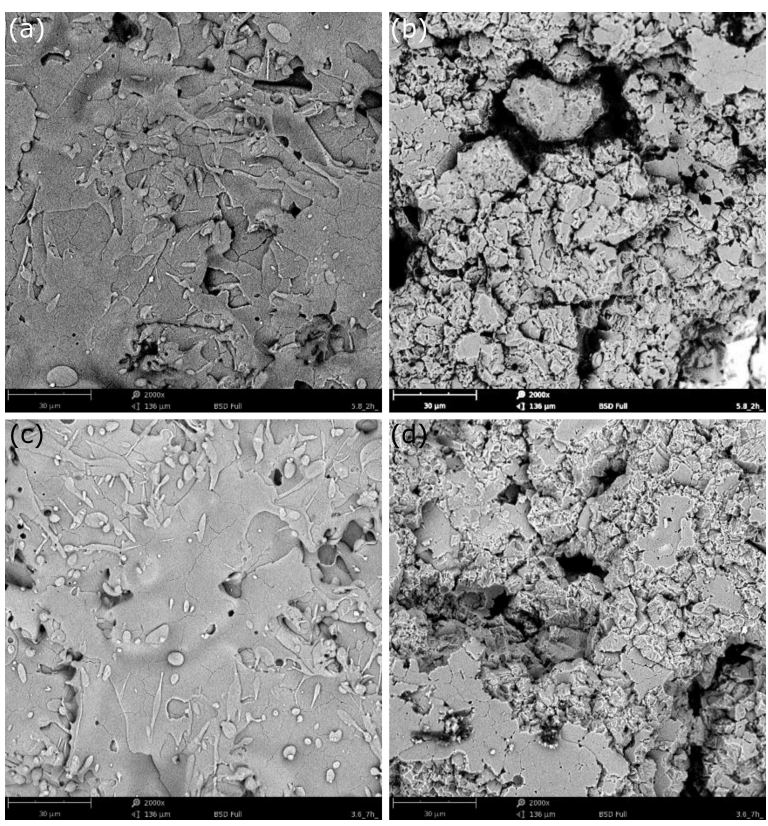

Fig. 5. Topography of the as-sprayed coatings (left images) and topography after the CER tests (right images) of selected manufactured coatings: (a, b) - AT13-5 (after $4 \mathrm{~h})$ and $(\mathrm{c}, \mathrm{d})$ - AT13-3 (after $9 \mathrm{~h})$, SEM-BED, mag. $\times 2000$

The curves in Fig. 4 indicate that incubation time of coatings is negligible contrary to the reference metal specimen, and exhibits almost a linear mass loss. These findings are in agreement with the literature results given for 
TABLE II

Parameters describing the cavitation erosion process of ceramic coatings and reference (304)

\begin{tabular}{l|c|c|c|c}
\hline \hline Specimen & $\begin{array}{c}\text { Max. erosion } \\
\text { rate }[\mathrm{mg} / \mathrm{h}]\end{array}$ & $\begin{array}{c}\text { MDE } \\
{[\mu \mathrm{m}]}\end{array}$ & $\begin{array}{c}\text { MER } \\
{[\mu \mathrm{m} / \mathrm{h}]}\end{array}$ & $\begin{array}{c}\mathrm{Ne} \\
{[-]}\end{array}$ \\
\hline AT13-1 & 3.58 & 12.219 & 3.055 & 0.31 \\
AT13-2 & 2.50 & 12.597 & 3.149 & 0.30 \\
AT13-3 & 2.22 & 10.834 & 2.708 & 0.35 \\
AT13-4 & 3.78 & 14.613 & 3.653 & 0.26 \\
AT13-5 & 3.28 & 11.338 & 2.834 & 0.33 \\
304 & 0.49 & 3.747 & 0.937 & 1.00
\end{tabular}

TABLE III

Roughness of coatings and reference sample at different exposure time

\begin{tabular}{l|c|c|c|c}
\hline \hline \multirow{2}{*}{ Specimen } & \multicolumn{2}{|c|}{ Before testing } & \multicolumn{2}{c}{ After $240 \mathrm{~min}$} \\
\cline { 2 - 5 } & $S_{a}(\mu \mathrm{m})$ & $S_{z}(\mu \mathrm{m})$ & $S_{a}(\mu \mathrm{m})$ & $S_{z}(\mu \mathrm{m})$ \\
\hline AT13-1 & 5.8 & 75.7 & 6.1 & 59.1 \\
AT13-2 & 5.7 & 70.7 & 7.0 & 84.3 \\
AT13-3 & 5.4 & 67.3 & 6.2 & 65.7 \\
AT13-4 & 6.1 & 62.7 & 6.8 & 75.4 \\
AT13-5 & 6.2 & 71.5 & 6.5 & 91.9 \\
304 & 0.2 & 11.3 & 1.3 & 22.1
\end{tabular}

the ceramic bearing coatings $[9,25,29,34]$. The analysis of the cavitation erosion results (Figs. 4 and 2) allow to state that the coatings exhibit the maximal erosion rate at a relatively short period of time (after 10 mins of testing) and the constant erosion rate till $60 \mathrm{~min}$ of exposure whereas the reference steel (304) starts to erode after the incubation time that lasts 30 min of cavitation. On the whole, the reference (304) sample exhibits higher CER than the ceramic coatings (Table II) and the coating AT13-3 exhibits the highest resistance to cavitation erosion. Thus it can be stated that spraying with the parameters: $h=90 \mathrm{~mm}$ and $V=400 \mathrm{~m} / \mathrm{s}$ results in deposition of the highest CER coating, AT13-3.

The obtained results of cavitation erosion testing are comparable with those presented in the literature. Jafarzadeh et al. [18] investigated CER of aluminatitania coatings under the same testing conditions as ours (however, without any reference materials). Thus, the obtained results of mean depth of erosion MDE (Table II) are comparable with the values given in [18] (compared after $4 \mathrm{~h}$ of exposure). However in our research the mean erosion rate (MER) is lower (Table II). Moreover, the coating AT13-3 eroded twice more slowly (Table II) than reported in [25] for the highest resistance to the cavitation APS alumina-titania coating $(4.6 \mathrm{mg} / \mathrm{h})$ that can be derived from the different conditions of cavitation erosion testing. This can be explained by the fact that in [25] the standoff between sonotrode-specimen was $0.5 \mathrm{~mm}$ lower than in our experiment. It is known from the literature [35] that a smaller gap intensifies the cavitation erosion process.
Apart from the other tested coatings, investigated till the coating material accelerates dramatically, the AT13-3 specimen presents relatively low CER parameters during exposition to cavitation. It was investigated for $9 \mathrm{~h}$ of cavitation testing. Thus, the computed result indicates that the erosion process (erosion rate) of the sprayedcoating AT13-3 decelerates to $0.51 \mathrm{mg} / \mathrm{h}$, and to reference (304) erosion rate accelerates up to $0.52 \mathrm{mg} / \mathrm{h}$. Additionally, after $9 \mathrm{~h}$ of exposition to cavitation of AT13-3 coating, the estimated Ne parameter increased to 0.54 . The MER parameter of coatings was constant contrary to the reference sample MER which increased with the exposition time. This confirms that the cavitation erosion mechanism of metal alloys is different from that identified for ceramic materials. After $4 \mathrm{~h}$ of cavitation, the normalised cavitation erosion resitance $(\mathrm{Ne})$ was calculated by dividing the measured volume loss of the reference material by the volume loss of the coated samples, both tested under the same conditions.

The conducted analysis indicates that the computed cavitation erosion indicators (2), do not correlate with the hardness, porosity, or roughness parameters (given in Table III). Additionally, no relations between the stand distance $H$ and the torch velocity $V$ with the as-sprayed coating roughness or roughness measured after $4 \mathrm{~h}$ of testing were stated. However, the results of comparison of roughness measured after $4 \mathrm{~h}$ of exposure with the value of hardness and porosity confirmed the influence of porosity and hardness on the mechanism of coatings cavitation erosion. Table III indicates the increase of $S_{a}$ parameter after $4 \mathrm{~h}$ of cavitation. Thus, the same findings were reported by Jafarzadeh et al. [18] who identified an increase of roughness of titatnia-alumina coatings with the increasing time of exposure. Besides the lowest roughness variation was observed for the AT13-3 coatings which revealed the lowest mass loss (Table II and Fig. 4). Moreover, the $S_{z}$ parameter decreases only for the coatings AT13-1 and AT-13-3 which present a denser microstructure with the porosity $2.30 \%$ and $2.91 \%$, respectively.

That is in agreement with the morphology of coatings AT13-3 and AT13-5 visible in Fig. 5. In fact, behaviour of coatings is affected by porosity and hardness. Relatively high hardness and low porosity (e.g. coating AT13-1) indicate heterogeneous erosion of surface (represented by low $S_{a}$ and $S_{t}$ values) contrary to the AT13-2 coating which presents developed surface pitting. These observations suggest that the coatings with the dense structure demonstrate a uniformly worn surface after the cavitation exposition.

The cavitation worn coatings are presented in Figs. 5 and 6 . Therefore, it is worth adding that the plasma spray parameters do not affect the cavitation erosion wear mechanism of the kind of coatings, as shown on Fig. 5.

Our investigations on the cavitation erosion mechanism of AT13 coatings (see Fig. 5 are in agreement with the literature reports. The cavitation erosion mechanism 


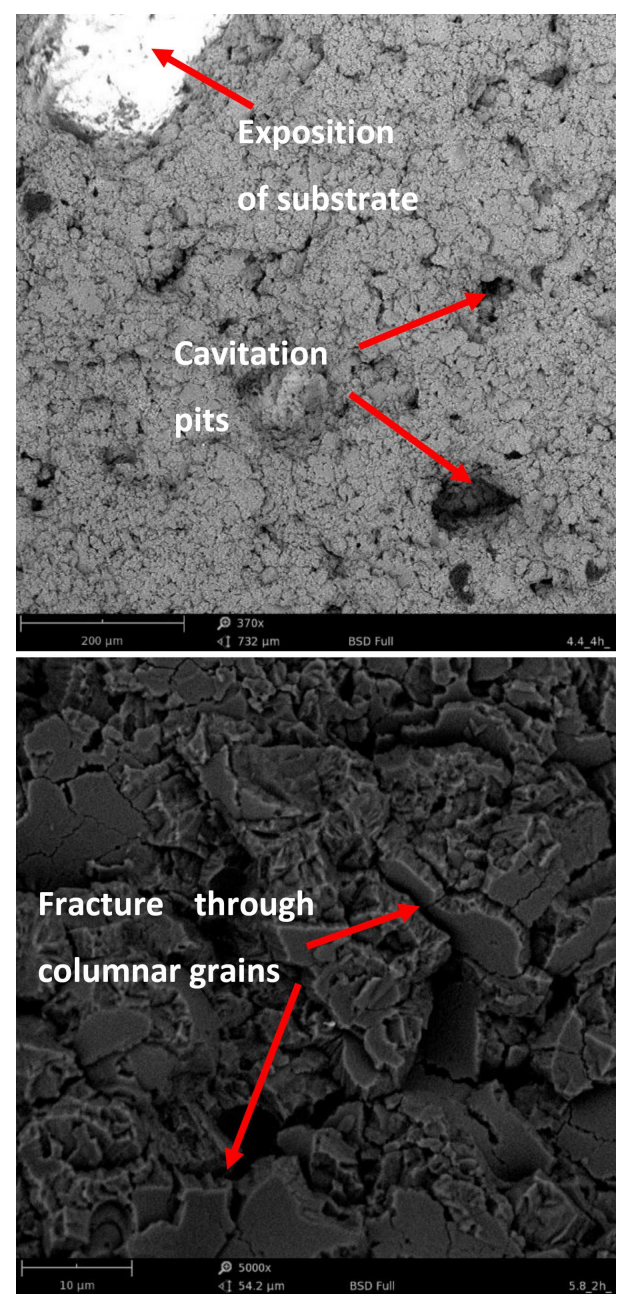

Fig. 6. Overview of degraded coating AT13-4 (a) and magnified cavitation eroded area of coating AT13-5 (b), SEM-BSD.

of the coating starts in initial defects such as pores, microcracks, and areas of incomplete contact between lamellas, accompanied by removal of overlapping splats, loose lamellas, and further consists of pit formation followed by coalesce and development of coating (initial) microcracks or brittle cracking of splats that undergo cavitation. Crack propagation towards the substrate accompanied by spallation of lamellas material and/or detachment of splat is also denoted. Therefore, craters were observed toward the substrate resulting in exposition of the steel substrate — visible for AT13-4 in Fig. 6.

- Figure 6a Even though the cavitation erosion wear mechanism of ceramic aluminia-titania coatings is well described in literature, one important feature is neglected $[18,25]$ i.e. influence of columnar growth of lamella grains. The investigated coating presents a typical lamellar structure and each splat consists of columnar crystals. This columnar structure is visible within the fracture-face of cavitation worn splats.
- Figure 6b Hence, it can be observed that spallation of lamellas proceeds parallel to the columnar grains borders. That is important information about mechanism of cavitation erosion of the subject for $\mathrm{Al}_{2} \mathrm{O}_{3}+13 \mathrm{wt} \% \mathrm{TiO}_{2}$ plasma sprayed coatings which was not discussed in the literature before. Therefore it should be added that the plasma spray parameters do not affect the general cavitation erosion wear mechanism of the kind of coatings, visible in Fig. 5.

\section{Conclusions}

On the basis of conducted research works the following conclusions can be drawn:

- the coating microstructure is strongly dependent on the selected process parameters;

- dependence between the microhardness values and the porosity level could be clearly seen i.e. the increase of porosity results in decreasing coatings hardness;

- observations of samples cross-section confirm that coating hardness is related to spray parameters. Decrease of hardness is a result of less compact structure and lower degree of well molten particle.

- APS process parameters influence on the cavitation erosion resistance of $\mathrm{Al}_{2} \mathrm{O}_{3}+13$ wt $\% \mathrm{TiO}_{2}$ coatings. Spraying with the parameters $h=90 \mathrm{~mm}$ and $V=400 \mathrm{~mm} / \mathrm{s}$ results in the deposition of the highest CER coating. The best cavitation erosion resistance was characteristic of centre experiment (Al13-3) which had a compact microstructure but not very high heat flux;

- porosity and microhardness are correlated with the roughness parameters $\left(S_{a}\right.$ and $\left.S_{z}\right)$ measured after $4 \mathrm{~h}$ of testing. Thus porosity and hardness influence coatings wear mechanism. Coatings revealing a dense structure demonstrate uniformly worn surface after the cavitation exposition. On the other hand, we agree with the statement made by Jafarzadeh et al. [18] that cavitation erosion resistance can be an estimator of coatings structure and cohesion as the coating defects are the major erosion accelerating factors.

- cavitation erosion mechanism of aluminatitania coatings is strongly affected by the lamellar structure and the splat columnar structure, thus cracking and the subsequent material detachment precede parallel to the columnar grains.

\section{References}

[1] F.L. Toma, L.M. Berger, C.C. Stahr, T. Naumann, S. Langner, J. Therm. Spray Technol. 19, 262 (2010).

[2] A. Góral, W. Żórawski, Przegląd Spawalnictwa 87, 34 (2015). 
[3] A. Maruszczyk, A. Dudek, M. Szala, Adv. Sci. Technol. Res. J. 11, 204 (2017).

[4] Y. Sert, N. Toplan, Mater. Technol. 27, 181 (2013).

[5] Material Product Data Sheet High Purity Aluminum Oxide Thermal Spray Powders, Oerlikon Metco.

[6] Material Product Data Sheet Aluminum Oxide 13\% Titanium Dioxide Powders, Oerlikon Metco.

[7] Material Product Data Sheet Aluminum Oxide 40\% Titanium Dioxide Powders, Oerlikon Metco.

[8] Y.M. Wang, H. Tian, X.E. Shen, L. Wen, J.H. Ouyang, Y. Zhou, D.C. Jia, L.X. Guo, Ceram. Int. 39, 2869 (2013).

[9] M. Szala, T. Hejwowski, Coatings 8, 254 (2018).

[10] V. Geaman, M.A. Pop, D.L. Motoc, I. Radomir, Eur. Sci. J. 9, (2014).

[11] E.P. Song, J. Ahn, S. Lee, N.J. Kim, Surf. Coat. Technol. 202, 3625 (2008)

[12] A.K. Berkath, A. Kumar, P.M. Suresh, Int. J. Innov. Res. Sci. Eng. Technol. 3, (2015).

[13] T.J. Steeper, D.J. Varacalle, G.C. Wilson, W.L. Riggs, A.J. Rotolico, J. Nerz, JTST 2, 251 (1993).

[14] Thermal Spray Coatings: Properties, Processes, and Applications: Proc. of the Fourth National Thermal Spray Conference, 1991, Ed. T.F. Bernecki, ASM International, Pittsburgh (PA) 1992.

[15] M. Wang, L.L. Shaw, Surf. Coat. Technol. 202, 34 (2007).

[16] V.P. Singh, A. Sil, R. Jayaganthan, Wear 272, 149 (2011).

[17] S.T. Aruna, N. Balaji, J. Shedthi, V.K.W. Grips, Surf. Coat. Technol. 208, 92 (2012).

[18] K. Jafarzadeh, Z. Valefi, B. Ghavidel, Surf. Coat. Technol. 205, 1850 (2010).

[19] Thermal Spray Materials Guide, Oerlikon Metc, 2018.

[20] J.A. Wahab, M.J. Ghazali, A.F.S. Baharin, MATEC Web Conf. 87, 02027 (2017).
[21] M.A. Zavareh, A.A.D.M. Sarhan, B.B.A. Razak, W.J. Basirun, Ceram. Int. 40, 14267 (2014).

[22] Y. Xing, J. Deng, Z. Wu, H. Cheng, Appl. Surf. Sci. 265, 823 (2013).

[23] E. Bannier, M. Vicent, E. Rayón, R. Benavente, M.D. Salvador, E. Sánchez, Appl. Surf. Sci. 316 , 141 (2014).

[24] W. Tian, Y. Wang, Y. Yang, Tribol. Int. 43, 876 (2010).

[25] V. Matikainen, K. Niemi, H. Koivuluoto, P. Vuoristo, Abrasion, Coatings 4, 18 (2014).

[26] W. Deng, Y. An, G. Hou, S. Li, H. Zhou, J. Chen, Ultrason. Sonochem. 46, 1 (2018).

[27] Y. Wang, G. Darut, T. Poirier, J. Stella, H. Liao, M.P. Planche, Tribol. Int. 111, 226 (2017).

[28] S. Goel, S. Björklund, N. Curry, U. Wiklund, S. Joshi, Surf. and Coat. Technol. 315, 80 (2017).

[29] E. Klyatskina, E. Rayón, G. Darut, M.D. Salvador, E. Sánchez, G. Montavon, Surf. Coat. Technol. 278 , 25 (2015).

[30] S. Guessasma, G. Montavon, C. Coddet, Comput. Mater. Sci. 29, 315 (2004).

[31] C. Pierlot, L. Pawlowski, M. Bigan, P. Chagnon, Surf. Coat. Technol. 202, 4483 (2008).

[32] ASTM E2109-01(2014) Standard Test Methods for Determining Area Percentage Porosity in Thermal Sprayed Coatings, ASTM International, West Conshohocken (PA) 2014.

[33] ASTM G32-10: Standard Test Method for Cavitation Erosion Using Vibratory Apparatus, ASTM International, West Conshohocken (PA) 2010.

[34] M. Szala, T. Hejwowski, I. Lenart, Adv. Sci. Technol. Res. J. 8, 36 (2014).

[35] J. Chmiel, W. Janicki, A. Krella, J. Steller, Problemy Eksploatacji 2010(1), 91 (2010). 